\title{
EXPERIÊNCIAS COM RESOLUÇÃO DE PROBLEMAS EM MATEMÁTICA EM ESCOLAS NO ESTADO DO RIO DE JANEIRO
}

\author{
EXPERIENCES WITH PROBLEM SOLVING IN MATHEMATICS IN RIO DE JANEIRO
}

STATE SCHOOLS

\author{
AUGUSTO CESAR DE CASTRO BARBOSA $a^{a}$ \\ CLAUDIA FERREIRA REIS CONCORDIDO ${ }^{b}$ \\ MARCUS VINICIUS TOVAR COSTA ${ }^{c}$
}

\begin{abstract}
Resumo
Neste trabalho buscamos apresentar uma coletânea de experiências realizadas em salas de aula de Matemática no Ensino Básico, em que optou-se pela metodologia de Resolução de Problemas. Essas experiências são fruto de diversos trabalhos desenvolvidos pelo Grupo "Resolução de Problemas e Ensino de Matemática" do Instituto de Matemática e Estatística da Universidade do Estado do Rio de Janeiro. Além de estabelecermos os fundamentos da Resolução de Problemas, descrevemos brevemente como se desenvolveu cada uma dessas experiências e os ensinamentos que colhemos. Tivemos então a oportunidade de investigar a eficácia dessa metodologia no processo de ensino-aprendizagem considerando vários tópicos do programa de Matemática, tanto do Ensino Fundamental quanto do Ensino Médio, bem como envolvendo diferentes realidades sociais.
\end{abstract}

Palavras chave: Ensino de Matemática, Resolução de Problemas, Ensino Básico.

\begin{abstract}
In this work, we present a collection of experiments carried out in Basic Education Mathematics classrooms, adopting the Problem Solving methodology. These experiences are the result of several works developed by the Group "Problems Solving and Mathematics Teaching" of the Mathematics and Statistics Institute from Rio de Janeiro State University. In addition, we briefly describe how each one of those experiences was developed along with the lessons we learned, and the foundations of the Problem Solving. Hence, we took the opportunity to investigate this

${ }^{a}$ Departamento de Matemática Aplicada, Instituto de Matemática e Estatística - IME, Universidade do Estado do Rio de Janeiro - UERJ, Rio de Janeiro, RJ, Brasil; ORCID: 0000-0002-5094-1509 E-mail: accb@ime.uerj.br

${ }^{b}$ Departamento de Análise Matemática, Instituto de Matemática e Estatística - IME, Universidade do Estado do Rio de Janeiro - UERJ, Rio de Janeiro, RJ, Brasil; ORCID: 0000.0002.0767.9170 E-mail: concordido@ime.uerj.br

${ }^{c}$ Departamento de Matemática Aplicada, Instituto de Matemática e Estatística - IME, Universidade do Estado do Rio de Janeiro - UERJ, Rio de Janeiro, RJ, Brasil; ORCID: 0000.0002.9029.2507 E-mail: marcus.tovar@ime.uerj.br
\end{abstract}


methodology and its effectiveness in the teaching-learning process taking accout several current topics of the Mathematics Program, both in Elementary and Secondary Education, considering different social realities.

Keywords: Mathematics Teaching, Problem Solving, Basic School.

MSC2020: 97C70, 97D40, 97D50

\section{Introdução}

Um elemento que tem uma considerável influência no nosso sistema educacional, e tem servido como um referencial na busca de aprimoramento são as avaliações nacionais e internacionais como, por exemplo, o Programa Internacional de Avaliação dos Alunos (PISA). Apesar de todas as suas limitações no que tange às diversas tarefas desenvolvidas na escola, esse tipo de avaliação fornece informações relevantes sobre o processo ensinoaprendizagem, o que nos permite ter mais elementos para um planejamento estratégico de melhor qualidade. Em Matemática, em particular, o resultado do PISA de 2018 colocou o Brasil bastante abaixo da média mundial, ocupando a colocação 71 em um ranking que envolveu 79 países [11]. Este mau desempenho é resultado de vários fatores, dos quais podemos destacar o ensino repetitivo e mecânico, que exige pouco raciocínio, e a falta de conexão entre a Matemática ensinada na escola e a que está presente no cotidiano do aluno [7].

Conforme Onuchic e Allevato [16], a Matemática é uma área do conhecimento que surgiu e tem se desenvolvido a partir de problemas que a humanidade encontrou. Pesquisas na área de Educação Matemática apontam que a metodologia Resolução de Problemas (RP) pode proporcionar aos alunos um caminho seguro para desenvolver uma aprendizagem mais significativa nas aulas de Matemática [16, 10].

Segundo os PCN - Matemática [5], o que se pretende com essa metodologia não é a mera reprodução de conceitos, procedimentos ou técnicas, em sala de aula, na resolução de um problema. A ideia é que o problema possa desempenhar o papel de um ponto de partida das aulas de Matemática, de forma que os conceitos, as definições e os métodos matemáticos sejam construídos com os alunos enquanto o problema proposto é resolvido, permitindo, além disso, que esses alunos criem questionamentos e possam desenvolver o raciocínio lógico [16, 10].

Este trabalho tem como principal objetivo apresentar as bases da metodologia de RP no processo de ensino-aprendizagem da Matemática. Apresentaremos também relatos de experiências envolvendo diversos tópicos, em ambientes escolares distintos, que nos permitiram selecionar alguns elementos capazes de pavimentar um caminho que torne a aplicação desta metodologia mais eficaz.

\section{A Resolução de Problemas}

A metodologia de RP tem se mostrado uma ferramenta importantíssima para incentivar o aluno a gostar de Matemática e, consequentemente, melhorar seu desempenho. Por meio dessa metodologia, com o objetivo de encontrar respostas para suas indagações, 
os alunos desenvolvem suas capacidades intelectuais e mobilizam estratégias, tais como: criatividade, intuição, autonomia, liberdade, tentativa e erro, entre outras [21].

Para um bom entendimento do que venha a ser a metodologia de RP é fundamental que se estabeleça a diferença entre problemas e exercícios, no contexto que estamos abordando. Podemos entender o exercício como uma tarefa em que o aluno automatiza certas técnicas de resolução. O problema pode ser definido como uma tarefa que depende de organização e de alguns processos mais sofisticados que contam, principalmente, com o interesse e o comprometimento do aluno, envolvendo interpretação, poder de decisão e raciocínio dedutivo [15].

Para Polya [18], uma pessoa está diante de um problema quando ela se defronta com uma questão que não consegue resolver com o conhecimento que possui, e sua resolução deve seguir quatro etapas: compreender o problema; estabelecer um plano de ação; executar o plano e fazer o retrospecto ou verificação. Polya foi o primeiro a apresentar uma heurística na RP de Matemática. Suas ideias foram influenciadas por Descartes, Skinner e Wallas e seu trabalho influenciou grandes pesquisadores nesta área. A primeira etapa estabelecida por Polya propõe que jamais algum fato seja aceito como verdadeiro, se ainda existir alguma possibilidade de colocá-lo em dúvida. Na segunda etapa deve-se dividir cada uma das dificuldades encontradas em tantas partes quanto possível e, dessa forma, resolvê-las. A terceira coloca como o caminho lógico a ser seguido ordenar o raciocínio, iniciando um estudo a partir dos objetos mais simples para, gradativamente, atingir o mais complexo. Na última etapa, deve-se rever todo o processo de forma a se certificar de que nada foi omitido.

O método de Polya é um método de RP matemáticos, mas ele não descreve as etapas para resolvê-lo. Pode-se dizer que o método de Polya ensina a pensar o problema de modo a descobrir a solução, ou seja, a técnica que vai fazer com que o problema seja resolvido.

De acordo com Onuchic e Allevato [16], a RP deve ser separada em três etapas: a primeira etapa - antes - , em que o professor deve garantir que os alunos estejam mentalmente prontos para receber a tarefa e deve ser assegurado que todas as expectativas estejam claras; na segunda etapa - durante -, os alunos devem trabalhar e o professor observar e avaliar esse trabalho; finalmente - depois -, o professor deve aceitar a solução dos alunos e conduzir a discussão enquanto os alunos justificam e avaliam os resultados obtidos e os métodos utilizados.

Para Onuchic e Allevato [17], trabalhar com a RP exige dos professores e alunos novas posturas e atitudes em relação ao trabalho desenvolvido em sala de aula. $\mathrm{O}$ professor tem também a tarefa de escolher os problemas adequados ao conceito que será construído. Por outro lado, os alunos passam a ter uma maior participação e responsabilidade no processo de aprendizagem.

No final do século XX e início do século XXI, surgem no Brasil os Parâmetros Curriculares Nacionais (PCN), que trazem uma proposta sobre como trabalhar a RP nas aulas de Matemática. De acordo com os PCN, a RP pode ser entendida como o ponto de partida da atividade matemática, em vez de se lançar mão de uma simples execução de procedimentos e o acúmulo de informações. O potencial dessa metodologia é o de possibilitar aos estudantes a mobilização dos conhecimentos e o gerenciamento das informações que estão à sua disposição. Ainda segundo os PCN [6], a opção por organizar o trabalho pedagógico a partir da RP traz implícita a convicção de que o conhecimento matemático ganha significado quando os alunos têm situações desafiadoras para resolver e trabalham para desenvolver estratégias para resolvê-las. 
Acreditamos que a metodologia deva ser a espinha dorsal da forma de se estruturar as aulas de Matemática, para que o aprendizado ocorra de uma forma efetiva. Contudo, conforme colocam Onuchic e Allevato [17], é preciso ainda tratar de questões importantes: a maioria dos professores de Matemática está preparada para este tipo de abordagem? Como utilizar todas as técnicas envolvidas nessa metodologia, levando-se em conta que há prazos para a apresentação dos conteúdos e a utilização em larga escala de apostilas padronizadas, dada a importância no ENEM em nosso sistema de ensino?

Enfim, como metodologia de ensino, a RP pode fazer com que os conceitos e princípios matemáticos se tornem mais claros para os alunos, na medida que eles podem ser elaborados, adquiridos e investigados de maneira bastante ativa e mais significativa. Além disso, as diversas experiências realizadas indicam que a RP em Matemática tende a auxiliar o desenvolvimento e o aprimoramento do raciocínio, da capacidade de expressão e da imaginação.

\section{Algumas Experiências}

Vamos colocar nessa seção algumas experiências realizadas em escolas no Estado do Rio de Janeiro, em ambientes distintos, abordando conteúdos diferentes.

\subsection{Primeira Experiência - Uma Aplicação de RP no Estudo das Equações do $2^{\circ}$ Grau}

Na primeira experiência, a metodologia de RP foi empregada para a introdução de equações do $2^{\circ}$ grau, que faz parte dos conteúdos do nono ano do Ensino Fundamental. Esta experiência ocorreu em uma escola particular, localizada no bairro de Pendotiba, município de Niterói, no estado do Rio de Janeiro. A turma era composta por 27 alunos com idades entre 14 e 15 anos. O livro de Matemática utilizado durante o ano foi o Araribá Plus Matemática 9o ano, além do caderno de atividades que o acompanha, composto por exercícios de fixação e de problemas. A apresentação de um novo conteúdo nesse livro sempre ocorre através de um problema, fato que foi ao encontro do que se pretendia desenvolver. Os métodos de resolução dessas equações foram discutidos segundo os seguintes modelos: método de completar quadrados, fórmula de Bhaskara, relação entre os coeficientes e as raízes de uma equação e método geométrico de Al-Khwarizmi.

O livro inicia a unidade de interesse apresentando o seguinte problema: "Juliana fez um tapete para enfeitar seu quarto (Figura 1). Para fazer esse tapete, Juliana costurou, uns nos outros, retalhos de tecidos de formato quadrado, todos com as mesmas dimensões. Sabendo que o tapete ficou com $4.050 \mathrm{~cm}^{2}$, como podemos calcular quanto mede o lado de cada quadrado de retalho?".

Não houve grandes dificuldades para os alunos compreenderem que o lado de cada quadrado seria a incógnita $x$. Como o comprimento do tapete tem 10 quadrados e a largura tem 5, as medidas dos lados do tapete serão, respectivamente, $10 x$ e $5 x$. Como o tapete tem formato retangular, a sua área será dada pela área do retângulo, isto é $S=$ $10 x \times 5 x$. Assim, podemos construir a equação: $S=10 x \times 5 x=4.050,50 x^{2}=4.050$, ou $50 x^{2}-4.050=0$.

Logo em seguida o livro estabelece a definição de equação do $2^{\circ}$ grau, com incógnita $x$, como aquela que pode ser escrita na forma $a x^{2}+b x+c=0$, onde $a, b$ e $c$ 
Figura 1: Problema que introduz o tópico equações do $2^{\mathrm{o}}$ grau.

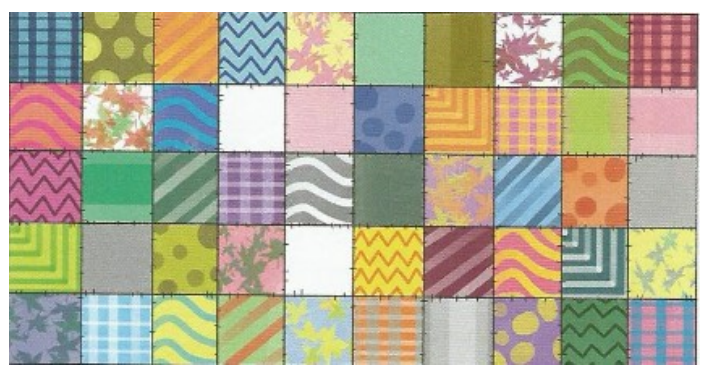

Fonte: Araribá Plus Matemática 9oano, 2014, p. 54, [19].

são números reais e $a \neq 0$. Os números $a, b$ e $c$ são chamados coeficientes da equação, que pode ser classificada como completa ou incompleta, de acordo com os valores desses coeficientes. O livro então recorda que raiz de uma equação é o valor atribuído à incógnita que torna a sentença matemática verdadeira. Para finalizar essa seção, o livro traz uma série de exercícios e problemas para serem trabalhados em sala. A abordagem desse livro foi seguida, com os problemas sendo complementados com aqueles do caderno de atividades.

Um vídeo do Telecurso $2000{ }^{d}$ sobre o método de completar quadrados foi apresentado aos alunos. O vídeo traz uma situação-problema como motivação para a compreensão do método de completar quadrados. Quando os alunos terminaram de responder as questões propostas no vídeo, eles foram desafiados a resolver equações utilizando o método de completar quadrados e a responder perguntas sobre questões levantadas.

Como o livro não apresenta problemas para iniciar a parte de resolução de equações do $2^{\underline{o}}$ grau incompletas, algumas atividades foram apresentadas para a turma. Segue um exemplo das atividades desenvolvidas em sala de aula como continuidade do trabalho com as equações do $2^{\circ}$ grau, para ilustrar a aplicação da resolução de problemas.

Figura 2: Problema que introduz o tópico equações do $2^{\circ}$ grau.

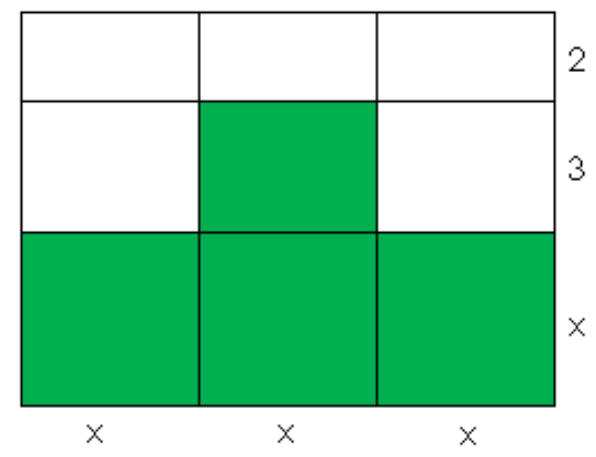

Fonte: Os autores.

Nesse problema, a incógnita $x$ já está definida na Figura 2. Assim, a área da parte verde é indicada por $3 x^{2}+3 x$ e deve ser igual a 60 conforme o enunciado. Dessa forma, o problema é modelado pela equação $3 x^{2}+3 x-60=0$, cujas soluções são -5 e 4 . Como

\footnotetext{
${ }^{d}$ https://www.youtube.com/watch?v=4LvnEGtrqVg
} 
$x$ é o lado de um polígono, a solução é $x=4$. Vale mencionar que, para achar as raízes da equação, 2 alunos utilizaram a fórmula de Bhaskara e 25 utilizaram relação entre os coeficientes e as raízes da equação (envolvendo soma e produto); nenhum aluno optou pelo método de completar quadrados ou pelo método de Al-Kharizmi.

As atividades desenvolvidas nessa primeira experiência foram formadas por problemas como os que descrevemos e por exercícios clássicos de fixação, envolvendo equações do $2^{\underline{o}}$ grau. Após a aplicação dessas atividades, observamos a preferência dos alunos pela fórmula de Bhaskara, com poucos alunos tentando resolver as equações pelo método de completar quadrados. O método geométrico de Al-Khwarizmi não foi aderido por nenhum aluno. Depois de cumpridas todas as atividades, alguns alunos ainda se arriscaram a resolver os problemas utilizando esse método, mas com o passar do tempo, eles acabaram deixando-o de lado, [7].

Acreditamos que essa experiência contribuiu para que os alunos envolvidos tenham conseguido um melhor entendimento do conteúdo abordado, envolvendo como mencionamos situações contextualizadas, o que certamente concorreu para um aprendizado mais efetivo.

\subsection{Segunda Experiência - A RP no Ensino de Matrizes}

Nosso objetivo na segunda experiência foi introduzir o conceito de matrizes a partir da resolução de problemas. Normalmente, esse tópico de Álgebra Linear é apresentado aos alunos do Ensino Médio a partir de suas definições e propriedades. Contudo, acreditamos que essa, provavelmente, não seja a melhor forma, pois a Matemática, nesse nível, concorre para estruturar o pensamento e o raciocínio dedutivo, além de fornecer ferramentas que servem para a vida cotidiana [6].

O conteúdo abordado nessa pesquisa se refere à introdução da linguagem matricial, operações entre matrizes e a resolução de sistemas. Essa experiência foi realizada em turmas do 3ํ ano do Ensino Médio de uma escola pública tradicional da cidade do Rio de Janeiro [3].

A experiência envolveu cinco turmas. Em duas delas, contando com 53 alunos no total, os problemas foram introduzidos após a apresentação formal do conteúdo, como, em geral, é feito; esses 53 alunos formam o Grupo 1. O Grupo 2 foi formado pelas outras 3 turmas, com um total de 79 alunos, em que os problemas foram apresentados antes da apresentação formal de matrizes. Vale mencionar que nas 5 turmas o conteúdo foi apresentado de forma contextualizada, envolvendo temas presentes no cotidiano dos alunos. Os instrumentos para coleta de dados e cálculo das estatísticas foram os registros escritos pelos alunos em quatro listas de problemas resolvidas por eles em sala de aula.

A abordagem foi feita através do livro Matemática, do Professor Manoel Paiva, da Editora Moderna, segunda edição, e por listas de problemas extras. Apresentaremos a seguir um dos problemas que constaram da primeira lista de problemas para a solução em sala de aula, aplicada nas duas turmas do Grupo 1.

O objetivo desse problema foi abordar a multiplicação de matrizes através de uma situação-problema para que os alunos percebessem a eficácia de sua utilização. Mesmo tendo visto anteriormente o formalismo necessário para a devida abordagem do problema, alguns alunos se mostraram confusos ao organizar as tabelas, houve então a orientação do professor para que, apesar da liberdade de poder organizar da forma que eles desejassem, eles poderiam organizar os elementos do item (a) colocando os modelos (modelo 1, 
modelo 2 e modelo 3) na horizontal e os materiais (borracha, couro e tecido) na vertical. Devido à dificuldade encontrada, foi dito para os alunos que eles poderiam organizar a tabela (matriz) com os materiais (borracha, couro e tecido) na horizontal e o custo na vertical. A quase totalidade dos alunos não percebeu que, para encontrar a solução do item (c), as matrizes obtidas nos itens (a) e (b) deveriam ser multiplicadas.

Problema: Uma indústria utiliza borracha, couro e tecido para fazer três modelos de sapatos. No modelo 1 são feitos 2 sapatos de borracha, 1 de couro e 1 de tecido. No modelo 2 são feitos 1 sapato de borracha, 2 de couro e nenhum de tecido. No modelo 3 são feitos 2 sapatos de borracha, nenhum de couro e 2 de tecido. $O$ custo de cada sapato de borracha é de $\mathrm{R} \$ 10,00$, cada sapato de couro tem o custo de $\mathrm{R} \$ 50,00$ e cada sapato de tecido tem o custo de $\mathrm{R} \$ 30,00$.

(a) Organize as informações em uma tabela que represente a quantidade de sapatos de cada modelo em relação a cada material utilizado (borracha, couro e tecido).

(b) Organize as informações em uma tabela que relacione cada material utilizado com o custo unitário do sapato. Ou ainda, o custo de cada sapato de borracha, couro e tecido.

(c) Determine o custo total para confeccionar cada um dos modelos de sapato.

(d) Organize os dados encontrados no item anterior em uma tabela.

Em geral, os alunos conseguiram resolver esse problema, mesmo sem a utilização das operações entre matrizes. Parte dos alunos resolveu o problema interpretando os dados, coletando e organizando as informações em tabelas.

Para o Grupo 2, como mencionamos, os problemas foram aplicados antes da abordagem formal de operações entre matrizes. Essas turmas tiveram apenas uma aula introdutória de matrizes antes das aplicações, quando foi estabelecida a relação entre tabelas e matrizes, assim como identificar elementos a partir de sua posição - (linha e coluna). A ideia foi aplicar a teoria de RP através de uma atividade de aprendizagem. Os alunos foram orientados a resolver os problemas interpretando os dados e tentando relacionar os elementos contidos nas tabelas. As atividades aplicadas nesse grupo foram as mesmas utilizadas no Grupo 1.

Quase todos os alunos desse grupo resolveram o problema sem grandes dificuldades. Vale mencionar que alguns apresentaram dificuldades no entendimento do enunciado. Ao ler o enunciado com eles, o professor pediu que encontrassem uma tabela que relacionasse diretamente o custo total para confeccionar cada modelo, ou seja, uma tabela (matriz) Modelo $\times$ Custo. Dentre as soluções incorretas, pode ser destacada aquela na qual foi encontrado o custo total de cada tipo de material, desconsiderando que o custo de cada sapato se diferencia pelo material utilizado. Nesse caso, em relação à heurística de [18], houve algum problema na fase de compreensão da questão e na fase de verificação. Nenhum aluno resolveu o problema usando a multiplicação de matrizes; mas interpretando os dados estabelecidos no enunciado.

Comparando os dados do Grupo 1 com os do Grupo 2, verificamos que os desempenhos foram semelhantes. No entanto, ao avaliar as resoluções do Grupo 1, percebemos que os alunos não conseguiram aplicar os conceitos teóricos previamente trabalhados aos problemas. Em contrapartida, os alunos do Grupo 2 se mostraram mais interessados e aptos a conectar suas estratégias com a teoria sobre matrizes que foi apresentada a posteriori. 
Apesar do rendimento dos dois grupos serem aproximadamente iguais, a metodologia de RP se mostrou uma ferramenta eficiente no ensino de matrizes e, além disso, trouxe um diferencial importante às aulas, em que o aluno teve oportunidade de se deparar com desafios e de expor suas ideias. Vale mencionar que vários alunos lamentaram que a metodologia de RP tenho feito parte do ensino de Matemática apenas no terceiro ano, em especial, nessa oportunidade.

\subsection{Terceira Experiência - Introdução da Análise Combinatória no Ensino Fun- damental com Auxílio da RP}

A terceira experiência que descreveremos envolveu uma oficina, executada em 5 encontros de 110 minutos cada, ligada ao ensino de Análise Combinatória em turmas de 8ㅜ e 9a anos do Ensino Fundamental em uma escola pública localizada em uma comunidade pobre da Cidade do Rio de Janeiro [14]. Durante as oficinas foram reunidos dados a partir de notas de campo (diário do professor), gravações em áudio e registros produzidos pelos alunos.

Em Análise Combinatória, poderíamos considerar como problema uma questão do tipo: "Quando jogamos uma moeda três vezes, quantas sequências diferentes de cara e coroa podemos obter?". O exercício, nesse contexto, almeja simplesmente fixar uma certa técnica e esta é a razão pela qual ele também deve ser utilizado como uma ferramenta didática. O exemplo dado pode gerar no aluno o desenvolvimento do raciocínio lógico, bem como do senso crítico. Para resolver esta questão, o aluno pode adotar diversas estratégias diferentes. Uma delas seria, a partir da observação que existem somente dois resultados possíveis em cada lançamento - cara ou coroa -, listar as sequências possíveis; o aluno encontraria $2 \times 2 \times 2=8$.

Para essa experiência foi proposto um conjunto de atividades que permitisse construir os conceitos da Análise Combinatória através da metodologia de RP. Como foi mencionado, as atividades foram executadas em forma de oficina. Essa oficina foi também composta, para sua avaliação, de um pré-teste e de um pós-teste. Para formular as atividades, foram tomadas as seguintes fontes: a Olimpíada Brasileira de Matemática das Escolas Públicas (OBMEP), o Canguru de Matemática, que é uma competição internacional, cuja principal missão é a popularização da Matemática pelo mundo, o livro "Prelúdio à Análise Combinatória", dos autores Bachx, Poppe e Tavares [2], cuja proposta, pautada no princípio multiplicativo, foge do ensino tradicional da Análise Combinatória.

Como nas outras experiências, coube ao docente incentivar os alunos a criar estratégias e desenvolver argumentações para se tornarem mais aptos a explicar de forma clara suas ideias, acompanhar os trabalhos indagando a respeito de suas conjecturas, colaborar com o desenvolvimento do raciocínio combinatório por meio de questionamentos, dar suporte aos alunos e valorizar suas ideias, bem como avaliar o progresso de cada um deles.

Antes da realização das atividades, foi aplicado um pré-teste, com o intuito de aferir como se processa o raciocínio combinatório desses alunos que ainda não entraram em contato com o conteúdo da matéria. Ao final das atividades, aplicou-se um pósteste, com o propósito de analisar se houve ganhos decorrentes da realização das ações propostas.

Os encontros envolveram situações que abrangeram o princípio fundamental da contagem e o cálculo de permutações, arranjos e combinações. As atividades foram de- 
senvolvidas com a formação de grupos de quatro ou cinco alunos. Com isso houve a oportunidade de cada aluno debater as questões com os seus colegas de grupo e ampliar sua capacidade de cooperação e argumentação. As resoluções dos problemas foram compartilhadas após o término de cada uma das atividades, quando cada grupo expôs suas ideias para os demais alunos e para o docente.

O pré-teste individual foi aplicado no início do primeiro dia da oficina e composto pelas questões:

1. Daniela planeja ir à praia e deseja utilizar uma regata, um short e uma sandália. Sabe-se que ela possui 4 regatas, 2 shorts e 2 sandáias. De quantas formas diferentes Daniela poderá vestir-se?

2. De quantas formas diferentes 4 pessoas podem formar uma fila?

3. Quantos números de dois algarismos distintos podemos formar com os algaris$\operatorname{mos} 1,2,3,4,6$ e 7 ?

4. Numa circunferência são marcados 5 pontos. Determine o número de triângulos que podemos formar com vértices nestes pontos.

Nos encontros que se seguiram, diversas atividades em grupo foram realizadas com a apresentação de problemas que permitiram, além das discussões, a construção conceitual dos agrupamentos.

Alguns exemplos de problemas abordados nos demais encontros são apresentados a seguir.

1. Em um grupo de seis alunos, dois deles não se toleram e não desejam sair lado a lado em uma fotografia. De quantos modos diferentes esse grupo de alunos poderá posar para a fotografia, respeitando essa incompatibilidade?

2. Num grupo de alunos composto por 3 rapazes e 4 moças, de quantos modos pode-se escolher um representante e um vice representante para a turma?

No último dia foi aplicado o pós-teste, cujas questões apresentamos a seguir.

1. Frederico planeja ir à praia e deseja utilizar uma camiseta, uma bermuda e um chinelo. Sabe-se que ele possui 6 camisetas, 4 bermudas e 3 chinelos. De quantas formas diferentes Frederico poderá vestir-se?

2. De quantas formas diferentes 7 pessoas podem formar uma fila?

3. Quantos números de dois algarismos distintos podemos formar com os algaris$\operatorname{mos} 1,2,4,5,6,8$ e 9 ?

4. Numa circunferência são marcados 6 pontos. Determine o número de triângulos que podemos formar com vértices nestes pontos.

Nesta experiência procurou-se através da metodologia de RP mostrar a possibilidade de se introduzirem os conceitos básicos da Análise Combinatória no Ensino Fundamental. Acreditamos que a aprendizagem da Análise Combinatória possa ocorrer de uma forma mais significativa, ao se abandonar o ensino tradicional, normalmente baseado na memorização de fórmulas. O pano de fundo dessa proposta é a ideia que o ensino de Matemática pode se tornar mais interessante quando o aluno se depara com problemas desafiadores e significativos, ao invés de apenas exercícios que se distanciam do dia a dia 
e que exploram, principalmente, o uso de fórmulas.

\subsection{Quarta Experiência - Uso da RP e da Redução à Unidade como Facilitadores no Estudo de Proporcionalidade}

A quarta experiência envolveu uma proposta alternativa para o ensino de proporcionalidade, usando como metodologia a RP com foco no método de redução à unidade [12]. O ponto de partida é que entendemos que a abordagem usual sobre esse conceito em muitos casos pode não ser a mais adequada, dificultando assim o aprendizado por parte significativa dos alunos. Foi verificado através de um trabalho realizado na rede particular, em turmas do primeiro ano do Ensino Médio, que o conhecimento prévio acerca de proporcionalidade estava abaixo do que se esperava e que a proposta de ensino através da RP com o emprego da redução à unidade, se mostrou bastante satisfatória, como descrevemos a seguir.

O procedimento sugerido foi substituir, sempre que possível, as fórmulas pela redução à unidade ao apresentar o tema grandezas proporcionais. Dessa forma, a RP se mostrou uma alternativa adequada para despertar a curiosidade do aluno em relação aos tópicos a serem estudados e desenvolver, de forma eficiente, a capacidade de trabalhar esses tópicos. O tópico razão e proporção é usualmente introduzido no sétimo ano através de definições nos moldes das que seguem [1].

Definição: Duas variáveis $x$ e $y$ são diretamente proporcionais se existe uma constante positiva $k$ tal que $y=k x$. As variáveis $x$ e $y$ são inversamente proporcionais se $y=k / x$. Em ambos os casos, $k$ é chamada constante de proporcionalidade. do tipo

Definição: Se várias variáveis $x, y, z, w$ e $p$ estão relacionadas por uma equação

$$
p=k \frac{x \cdot y}{z . w}
$$

onde $k$ é uma constante positiva, então dizemos que $p$ é diretamente proporcional a $x$ e a $y$, e inversamente proporcional a $z$ e a $w$.

Lima [13] argumenta que, apesar de correta, a definição não é suficiente quanto à sua aplicabilidade. Ele aponta que para saber, por exemplo, se $p$ é diretamente proporcional a $x$ e a $y$, e inversamente proporcional a $z$ e a $w$, é necessário que o aluno conheça a fórmula (3.1), isto é, é necessário conhecer essas grandezas e suas propriedades, para daí então deduzir a proporcionalidade.

Uma forma alternativa que nos parece mais adequada para introduzir o conceito de razão e proporção é baseada na noção de redução à unidade. A vantagem dessa abordagem é o seu poder de síntese, pois tudo o que se tem a fazer é reduzir as informações à unidade e depois compará-la com o que se quer. Os livros comumente usados, como, por exemplo, Bianchini [4], Dolce e Pompeo [9], Silveira e Marques [22], omitem esse método em favor da utilização de um conjunto de fórmulas para resolver problemas. É como se o aluno encontrasse uma fórmula diferente para cada situação com que se depara, apesar de muitas vezes envolverem problemas de mesma natureza.

O método consiste em reduzir à unidade todas as variáveis envolvidas sob uma dada condição, através do uso de proporções. Depois de estabelecida tal condição, o passo seguinte é a transformação da sentença unitária na condição válida para a variável 
que se deve determinar por meio de multiplicação. O exemplo que segue ilustra esse método.

Problema: Três agricultores colhem 1.800 pés de alface em 5 horas. Se todos trabalham da mesma forma, quantos pés de alface serão colhidos em 6 horas por 2 agricultores?

Solução: A quantidade de pés de alface é diretamente proporcional ao número de agricultores e também ao número de horas trabalhadas. Portanto,

$$
3 \text { agricultores }-5 \mathrm{~h}-1.800 \text { pés de alface . }
$$

Se dividimos o número de agricultores por 3 , a quantidade de pés de alface também fica dividida por 3 ,

$$
1 \text { agricultor }-5 \mathrm{~h}-1800 / 3=600 \text { pés de alface } \text {. }
$$

Se dividimos o número de horas trabalhadas por 5 , a quantidade de pés de alface também fica dividida por 5 ,

$$
1 \text { agricultor }-1 \mathrm{~h}-600 / 5=120 \text { pés de alface } \text {. }
$$

Com a redução à unidade, sabemos agora quanto um agricultor colhe em uma hora, e daí podemos deduzir que, se multiplicamos o número de agricultores por 2 , a quantidade colhida também fica multiplicada por 2 ,

$$
2 \text { agricultores }-1 \mathrm{~h}-120 \times 2=240 \text { pés de alface } \text {. }
$$

Finalmente, se multiplicamos o número de horas por 6 a quantidade de pés de alface também fica multiplicada por 6 .

$$
2 \text { agricultores }-6 \mathrm{~h}-240 \text { × } 6=1440 \text { pés de alface . }
$$

Portanto, 2 agricultores colherão 1440 pés de alface em 6 horas.

Essa experiência foi realizada em turmas do primeiro ano do Ensino Médio de duas escolas da rede particular da cidade do Rio de Janeiro, uma localizada na Zona Norte (escola A), envolvendo três turmas (A1, A2, A3), e outra (escola B), da Zona Sul, com duas turmas (B1, B2). Vale mencionar que as duas escolas são conhecidas pelo bom padrão de ensino.

Para avaliar o conhecimento dos alunos sobre esse assunto, foi aplicado um teste de 12 questões nas cinco turmas. O Quadro 1 mostra o resultado desse teste, com o percentual de acertos.

Como pode ser visto do Quadro 1, o resultado foi ruim, abaixo do esperado, principalmente porque esse assunto já havia sido estudado no $7^{\circ}$ ano do Ensino Fundamental e pelo fato de a experiência ter sido implementada em duas boas escolas.

$\mathrm{O}$ assunto foi então abordado de duas formas diferentes: da forma tradicional, nas turmas A1 e B1, e com o método de redução à unidade nas demais. Em todas as turmas usamos a metodologia de RP. Após três aulas de 50 minutos, foi aplicado um teste com o mesmo nível de dificuldade do primeiro teste, com o intuito de avaliar o desempenho em 
Quadro 1: Resultados do teste preliminar sobre proporcionalidade.

\begin{tabular}{|l|c|c|c|c|c|}
\hline & Turma A1 & Turma A2 & Turma A3 & Turma B1 & Turma B2 \\
\hline & $(16$ alunos $)$ & $(19$ alunos $)$ & $(17$ alunos $)$ & $(20$ alunos $)$ & $(23$ alunos $)$ \\
\hline Acertos & $24,0 \%$ & $24,6 \%$ & $25,0 \%$ & $30,4 \%$ & $29,4 \%$ \\
\hline
\end{tabular}

Fonte: Os autores.

Quadro 2: Resultados do segundo teste sobre proporcionalidade.

\begin{tabular}{|l|c|c|c|c|c|}
\hline & Turma A1 & Turma A2 & Turma A3 & Turma B1 & Turma B2 \\
\hline & (16 alunos) & $(19$ alunos $)$ & $(17$ alunos $)$ & $(20$ alunos $)$ & (23 alunos) \\
\hline Acertos & $43,2 \%$ & $41,2 \%$ & $52,9 \%$ & $49,2 \%$ & $42,0 \%$ \\
\hline
\end{tabular}

Fonte: Os autores.

função das duas abordagens mencionadas. O Quadro 2 traz a percentagem de acertos por turma do segundo teste.

Nesta experiência, mostramos a viabilidade de se abordar o tema proporcionalidade por meio da redução à unidade, através da metodologia de RP, envolvendo problemas com diversos níveis de dificuldade. A metodologia de RP se mostrou bastante eficiente como suporte didático e motivacional para as atividades em sala de aula; acreditamos que essa eficiência, do ponto de vista didático, seja a razão dos resultados dos testes, envolvendo as abordagens tradicional e de redução à unidade, terem sido aproximadamente iguais. A baixa compreensão do conceito de grandezas proporcionais tem como consequência o fraco entendimento de diversos conceitos a ele relacionados como, por exemplo, a relação entre as variáveis de uma função afim, problemas envolvendo escalas e comparação entre áreas ou volumes de figuras geométricas. A ideia também presente nesta experiência é que o aluno pode ser preparado a resolver problemas que envolvem grandezas proporcionais sem fazer uso de fórmulas, ou mesmo sem precisar de um grande conhecimento acerca da natureza dessas grandezas [12].

\subsection{Quinta Experiência - Ensino de Matemática através da RP em Escolas das Redes Estadual e Municipal do Rio de Janeiro}

A quinta experiência também teve como meta investigar a eficácia do uso da metodologia de RP no processo de ensino-aprendizagem em Matemática. O trabalho se desenvolveu em duas frentes: uma delas foi a observação da experiência da Secretaria de Estado de Educação do Rio de Janeiro (SEEDUC) com a disciplina Resolução de Problemas Matemáticos (RPM), criada em 2012 e cujo principal objetivo é desenvolver no aluno a capacidade de resolver situações-problema referentes a seu nível escolar, a fim de que o raciocínio matemático desenvolvido auxilie o professor da disciplina do curso regular na abordagem dos conteúdos [20]; a outra foi a implementação de atividades com alunos de uma escola municipal do bairro de Realengo no Rio de Janeiro.

Após seis anos da implantação da disciplina RPM, uma questão pertinente e que deveria ser avaliada era se a disciplina havia cumprido as metas traçadas pela SEEDUC. 
Para tentar responder essa pergunta, foi realizada uma pesquisa com professores de Matemática de várias escolas estaduais. Foi elaborado um questionário, onde as respostas foram confrontadas com uma pesquisa realizada em 2016 [10]. Na pesquisa de 2016 foi constatado que somente uma pequena parcela (menos de 6\%) dos professores participantes não conhecia o principal objetivo da SEEDUC com a disciplina RPM, fato este que também foi confirmado pela nova pesquisa. Uma outra constatação foi a falta de capacitação e suporte para os professores trabalharem com a disciplina.

As atividades em sala de aula envolveram três turmas de 9o ano do Ensino Fundamental (1901, 1902 e 1903). Na 1901 foram realizadas aulas sobre trigonometria, seguindo a metodologia de RP, enquanto que nas duas outras o assunto foi abordado da forma tradicional. Houve em seguida a aplicação de um teste de avaliação composto de 5 problemas. As questões podem ser classificadas como problemas de aplicação, pois envolviam situações-problema contextualizadas que retrataram situações reais do dia a dia. O objetivo principal das questões foi verificar se os alunos sabiam utilizar os conceitos de seno, cosseno e tangente de forma correta e se seriam capazes de solucionar problemas aplicando os conceitos de razões trigonométricas, vistos em sala de aula. Apresentamos a seguir um dos problemas do teste.

Problema: Um aluno precisa acessar o topo de um muro de $3 \mathrm{~m}$ de altura. Para isto, ele deve apoiar uma escada no topo muro, de maneira que a escada forme um ângulo de $45^{\circ}$ com o solo. A que distância do muro o aluno deve colocar a base da escada?

A análise dos resultados mostrou que o rendimento (média de 4,1) da turma 1901, composta de 35 alunos, foi superior ao das demais (média de 2,0), que contaram com 43 alunos. Mais uma vez tivemos a indicação que a metodologia de RP pode, de fato, representar um ganho de qualidade no processo de ensino-aprendizagem da Matemática. Na pesquisa realizada por Gomes, de Castro Barbosa e Concordido [10], conjecturou-se que a disciplina RPM havia acabado, pois a matriz curricular de 2017 não havia mantido a disciplina, porém 18 (dezoito) professores responderam a nova pesquisa afirmando que continuam trabalhando com a disciplina e, além disso, a disciplina RPM continua a fazer parte das disciplinas regulares do currículo mínimo do Ensino Fundamental (anos finais) e Médio no site da SEEDUC. A nova pesquisa, realizada com alunos da Escola Municipal indicou que se a disciplina RPM fosse implementada em toda a rede Municipal do Rio de Janeiro haveria ganhos no processo de ensino-aprendizagem da Matemática [8].

Com o intuito de tornar mais eficaz a aplicação da metodologia de RP, propomos algumas sugestões: utilização dessa metodologia em todos os anos do Ensino Fundamental; oferecimento de capacitação para todos os professores interessados, de forma que possam aplicá-la adequadamente; promoção de seminários e de encontro de professores para que sejam trocadas experiências a respeito dessa metodologia.

\section{Considerações Finais}

A necessidade de resolver problemas sempre esteve relacionada com o dia a dia do ser humano no decorrer de sua história e, dessa forma, resolver problemas, por exemplo, 
em Matemática, deveria ser algo absolutamente normal e esperado. No entanto, não é o quadro que encontramos nas escolas no Brasil, onde verificamos, em geral, um desempenho dos alunos muito aquém do esperado quando o tema é a resolução de problemas.

A utilização da metodologia de RP nas aulas de Matemática tem como principal objetivo corrigir essa situação e permitir também que o aluno possa desenvolver habilidades e competências importantes, não apenas relacionadas à Matemática, mas também às demais disciplinas.

Apresentamos, de forma breve, cinco experiências desenvolvidas pelo Grupo de Pesquisa em Resolução de Problemas e Ensino de Matemática, do Instituto de Matemática e Estatística da Universidade do Estado do Rio de Janeiro. O ensino da Matemática, dentro dessa abordagem, pode se dar de três formas: ensinar sobre resolução de problemas, ensinar para resolução de problemas e ensinar por meio da resolução de problemas. Em geral, procuramos aplicar essa metodologia nas experiências em aulas de Matemática, colocando o problema como um ponto de partida para o professor desenvolver as ideias sobre determinado conteúdo.

Vimos que em todas as experiências narradas a metodologia de resolução de problemas se mostrou como uma eficiente ferramenta no processo ensino-aprendizagem de diversos tópicos de Matemática do Ensino Básico, que pode dar uma importante contribuição para que o aluno tenha um melhor entendimento dos conteúdos de Matemática a partir de uma situação contextualizada, o que pode contribuir para o estado de prontidão do aluno e um aprendizado mais efetivo.

\section{Agradecimentos}

Os autores agradecem o apoio da FAPERJ e CAPES a este trabalho.

\section{Referências}

[1] ÁVILA, G.: Razões, Proporções e Regra de Três. Revista do Professor de Matemática. São Paulo: SBM, v. 8, 1983.

[2] BACHX, A.C.; POPPE, L.M.B.; TAVARES, R.N.O.: Prelúdio à Análise Combinatória. Companhia Editora Nacional, 1975.

[3] BORGES, T. S.: A Metodologia de Resolução de Problemas no Ensino de Matrizes no Ensino Médio. Dissertação (Mestrado em PROFMAT) - Instituto de Matemática e Estatística, Universidade do Estado do Rio de Janeiro, Rio de Janeiro, 2018.

[4] BIANCHINI, E.: Matemática Bianchini. São Paulo: v.9. $7^{\text {a }}$ Moderna, 2011.

[5] BRASIL. Ministério da Educação e do Desporto. Secretaria de Educação Fundamental.: Parâmetros Curriculares Nacionais: Matemática - 1o e 2o ciclos. Brasília: MEC / SEF, 1997.

[6] BRASIL. Secretaria de Educação Fundamental.: Parâmetros Curriculares Nacionais: Matemática. Secretaria de Educação Fundamental. Brasília: MEC/SEF, 1998. 
[7] COUTINHO, R. P. et al.: Resolução de Problemas em Matemática - Uma Aplicação. Educação, Saúde e Ambiente, v. 9(3), p. 249-268, 2016.

[8] CUNHA, A. F.: Ensino de Matemática Através da Resolução de Problemas: uma proposta para escolas da rede do Município do Rio de Janeiro. Dissertação (Mestrado em PROFMAT) - Instituto de Matemática e Estatística, Universidade do Estado do Rio de Janeiro, Rio de Janeiro, 2019.

[9] DOLCE, O. e POMPEO, J.: Fundamentos de Matemática Elementar. São Paulo: v. 9, 9a ed., Editora Saraiva, 2013.

[10] GOMES, D. A.; CASTRO BARBOSA, A. C. de; CONCORDIDO, C. F. R.: Ensino de Matemática através da Resolução de Problemas: análise da disciplina RPM implantada pela SEEDUC-RJ. Educação Matemática Pesquisa, v. 19, p. 105-120, 2017.

[11] INEP (2019).: Relatório Brasil no PISA 2018: Brasília: MEC/INEP. Disponível em: http://download.inep.gov.br/acoes_internacionais/pisa/documentos/2019/relatorio_PISA_2018_preliminar.pdf. Acesso em: 04 abr. 2020.

[12] JACONIANO, E. A. et al.: Resolução de Problemas de Proporcionalidade por meio da Redução à Unidade. Educação Matemática em Revista, v. 24, p. 98, 2019.

[13] LIMA, E. L.: Que são Grandezas Proporcionais?. Revista do Professor de Matemática. São Paulo: SBM, 1986. v. 9.

[14] NASCIMENTO, R. A.: Análise Combinatória no Ensino Fundamental através da Resolução de Problemas. 2018. 108 f. Dissertação (PROFMAT) - Instituto de Matemática e Estatística, Universidade do Estado do Rio de Janeiro, Rio de Janeiro, 2018.

[15] ONUCHIC, L. R.: Ensino-Aprendizagem de Matemática através da Resolução de Problemas. In: BICUDO, M. A. V (Org.). Pesquisa em Educação Matemática: Concepções e Perspectivas. São Paulo: Ed. UNESP, 1999.

[16] ONUCHIC, L. R.; ALLEVATO, N. S. G.: Novas Reflexões sobre o Ensinoaprendizagem através da Resolução de Problemas. In: BICUDO, M. A. V.; BORBA, M. C. (Orgs.). Educação Matemática: pesquisa em movimento. São Paulo: Cortez, 2004.

[17] _ _.: Pesquisa em Resolução de Problemas: caminhos, avanços e novas perspectivas. Boletim de Educação Matemática, Rio Claro, v. 25, n. 41, p. 73-98, dez. 2011.

[18] POLYA, G.: A Arte de Resolver Problemas. 2. ed. Rio de Janeiro: Ed. Interciência, 2006.

[19] Projeto Araribá Plus - Matemática, 9o- ano. São Paulo: 4aㅡ. Ed., Editora Moderna, 2014.

[20] RIO DE JANEIRO. Secretaria de Estado de Educação.: Avaliação Interna da Aprendizagem: Manual de orientações para operacionalização da Portaria SEEDUC/SUGEN N 419/2013. Rio de Janeiro: SEEDUC, 2013. 
[21] ROMANATTO, M. C.: Resolução de Problemas nas Aulas de Matemática. Revista Eletrônica de Educação. São Carlos, SP: UFSCar, v. 6, no. 1, p.299-311, 2012.

[22] SILVEIRA, E.; MARQUES, C.: Matemática - Compreensão e Prática. v. 9. $2^{\mathrm{a}}$ ed. São Paulo: Moderna, 2013. 